\title{
Refugee artists and memories of displacement: a visual semiotics analysis
}

\section{Introduction}

During the past few years, migration and the refugee crisis have been a constant element in the news, in the media and in political agendas. And yet, migratory movements are not a recent phenomenon. People have always moved between countries and continents, in search of better working opportunities or to escape life-threatening situations. The last decades, however, have witnessed a dramatic increase of mass movements of people from Syria, Afghanistan, Iraq and North Africa towards Europe. If the twentieth century was known as 'the century of the refugees', the twenty first century 'looks set to become known as the century of displacement and dispossession' (Chatty 2014, 76).

While there have been several studies both about the visual narratives of the refugee crisis in the media (Esses et al., 2013; Pamment et al., 2017; Baider and Kopytowska, 2017; Chouliaraki, 2013; Wright, 2002; Arcimaviciene and Baglama, 2018; Boyle, 2013) and about the visual discourses generated by cultural institutions through their work with refugees and migrants (Gouriévidis, 2014; Whitehead et al., 2016; Goodnow et al., 2008), little attention has been paid yet to the visual narratives emerging from artworks produced by refugee artists. This article focuses exactly on this. It examines the ways in which displaced artists represent, through their paintings, the human and cultural experience of displacement, their cultural traditions and the longing for home and how, by doing so, they become the visual and perhaps legitimate interpreters of the refugee crisis.

Therefore, this article aims to add to the growing body of literature on the visual discourses about the experience of displacement from the point of view of the refugees themselves. To do so, the article addresses the following questions: what are the visual narratives generated through the images of artworks produced by refugee artists and shared online? And, what can they tell us about displacement, dispossession and the cultural identity of refugees in the twentyfirst century?

The article has been structured into four main parts: the first section contextualises the notion of refugees across disciplines; the second section outlines the ways in which notions of cultural identity are being used here to frame the analysis of the refugees' artworks; the third section presents the methodological approach, including the use of the Facebook page Syria.Art as an open repository for the display of refugee art, the visual analysis applied to the refugee art and the interviews carried out with some of the artists themselves; finally the fourth and last section of the article analyses and interprets the data collected, by identifying three main visual narratives: The Necessity of the Journey, Living Cultures in Everyday Practices and The Keepers of Cultural Heritage and Identity. 
The article will argue that these visual narratives are concerned primarily with reminiscences about people, places and cultural practices that have been lost or are in danger of being lost because of the forced journey and displacement. Within this context, such visual narratives become part of an open repository, which mediates, re-organises and preserves memories, both personal and collective as a form of emotional survival and resilience. These narratives go beyond divisive stereotypes: instead they nurture empathy for the human condition of the refugees and universalise the migrant experience, while allowing to silently contest official narratives of marginalisation and victimhood in favour of resilience and cultural pride.

\section{The 'Refugee' across disciplines}

Over the past decades, a growing body of literature ranging from migration studies to memory studies, from social anthropology to heritage and media studies has been looking at forced and mass movements and at their social, cultural and economic effects (Malkki, 1996; Moores, 2012; Gourievidis, 2014; Makaremi, 2014). Such work has presented 'newly theorised conceptions of human spaces, movements, and identities, as well as of policies, sovereignty and governance' (Moores, 2012, 7) and identified some of the political, social, human and cultural challenges that societies face during the 'age of migration' (Castles and Miller, 2014). At the same time, though, research has shown the limitations of the past scholarly approaches to forced migration and displacement, including Eurocentric, history-focused and policy-driven perspectives, a lack of consideration for the voices and narratives of the refugees themselves and a hazy understanding of the different terms (Gatrell, 2015; Sigona, 2014; Hathaway, 2007; Chatty, 2014).

Within the encompassing term 'displaced people', the distinction between refugees, forced migrants and Internally Displaced People (IDPs) has been blurred into arbitrary, descriptive labels. This conflation of the terms does not always reflect the complex realities of forced (for refugees and internally displaced people) and coerced (for some migrants) movements. Refugees, in particular, have been considered 'as mute, helpless victims rather than specific persons', with unique histories and distinctive cultural identities (Elie, 2014, 30). This means that their individual motivations, social situations and personal experiences too have become absorbed into wider political, global discourses and imagery reported by refugee experts or by the Western relief officials (Agier, 2008; Malkki, 1996). Hence a clarification of the terms is needed.

According to Esses et al $(2017,70)$, the notion of 'refugee' has widened its scope: from being a political category, associated primarily with post-World War II Jewish refugees, it now comprises all those individuals who 'have fled war or other form of violence in their home country' and cannot return to their homes for fear of discrimination and death. The concept of IDPs is rather similar, in the sense that IDPs share with refugees the involuntary nature of the movement, which, though, happens within national borders. Conversely, forced migrants are individuals who have left their homes to live, study and work elsewhere. Their movement is relatively voluntary, as they are not in danger of being 
persecuted, neither their lives are at risk of direct threats in their countries of origin. According to the International Organisation for Migration, only in 2017, there were about 25.9 million registered refugees and forced migrants, who are increasingly perceived as a threat to the hosting countries (https://www.iom.int/global-migration-trends, accessed December 5, 2018). Indeed, migration has become less acceptable with policy-makers across Europe designing restrictive measures to try to control mass movements. Peter Scholten et al (2016), for instance, have examined the impact of EU policies on developing different narratives of immigrant integration, by advocating the need to rethink the nexus between migration-integration, through 'mainstreaming' integration measures. This is in the hope to facilitate the interaction with local communities and the government.

These adverse attitudes have heightened with the 2015 Syrian refugee crisis. The overbearing rise of right-wing ideologies in Europe and in the USA has been fuelling, in the public arena, negative representations of and prejudices towards refugees. Instrumental to this have been mass media which, often perpetuate visual discourses about social and cultural uncertainty. The phenomenon has been well documented in the media literature. For example, Harald Bauder (2009) has discussed how media have been key in Germany, in constructing and reinforcing national identity debates, by visually presenting the refugee crisis as a humanitarian, economic and security crisis and in turn, by shaping local governmental policies and attitudes.

Already Susan Sontag (2003) has pointed out how images of war can be manipulated to change meanings and attitudes in terms of the historical context in which they are viewed. Accordingly, Terence Wright (2002) has explored the ways in which the representations of refugees in the media may be grounded in historical Christian archetypes and how this determine how we see and categorise refugees. The representation in the mass media of the 2015 refugee crisis has actually manipulated the visual narratives about the crisis and presented refugees both as people in need and as 'enemies at the gates' wanting to invade the Western nations (Esses et al., 2013, 519). This media ambivalence has been further explored by Lilie Chouliaraki $(2012 ; 2013)$ through what she calls 'the spectacle of suffering'. In her work, Chouliaraki examines the ways in which the spectacle of suffering has the power to move and motivate the public so that they can act towards the human vulnerability observed. However, this willingness to act evokes a language of power, which at the ends, fails to humanise the refugees. Therefore, although there has been 'a shift from a humanitarian discourse of pity to a post humanitarian discourse of irony' (Chouliaraki, 2012, 13), both paradigms cannot resolve the ambivalence of refugee representations on the media, or even aknowledge the agency of refugees as individuals with their own will, wishes and personalities. This insolvability perpetuates and reinforces the media representations of refugees either as voiceless objects of humanitarian intervention or as dangerous threats as well as the ideological dichotomy of 'us' versus 'them' (Arcimaviciene and Baglama, 2018): in any case, this has an influence on the formation, redefinition and representation of refugees and their cultural identity. 
Work on visual art has explored the discourses, generated through artworks produced by refugees, about nostalgia, resilience, memory and dispossession, in relation to the European migration crisis (Pamment et al., 2017; Baider and Kopytowska, 2017). At the core of this work there is the idea of art as a creative process and as a universal language, spoken by and for refugees/forced migrants: it is often political and nevertheless it can connect, celebrate and 'heal' individuals, nations and cultures across the globe (Rotas, 2004). T. J. Demos, for instance, offers a set of examples of refugee and migrant artists - situated in Europe, North America, the Middle East and North Africa - who have been addressing through their work, questions 'regarding the relation between politics and aesthetics, mediums and mobility, socioeconomic disparity and emancipatory artistic promise' (2013, xiv). The main message is that artworks can inspire hope and optimism, despite restrictive social contexts and personal precarious and traumatic situations.

However, more attention should be placed towards visual narratives that universalise the migrant experience and which are collected, organised and shared in accessible, open repositories, like, for instance, social media. This article intends to fill this gap. Before discussing the artworks and the visual narratives associated with them, it is essential though to consider the relationship between refugees and cultural identity, as this would provide the conceptual framework for the following analysis.

\section{Cultural identity and refugees}

Cultural identity is a complex concept, which 'more or less everyone knows more or less what it means, and yet its precise definition proves slippery' (Lawler, 2008, 1). This is because cultural identity is connected both to sameness and difference. It is possible to think of cultural identity in terms of sameness, when we relate it to shared cultural elements, grounded in shared history. But when cultural identity is connected to the idea of difference, then it is a process, a matter of becoming as well as of being (Hall, 2000).

Therefore, with respect to the idea of difference, cultural identity is not only grounded in past, shared histories, but it is much more linked to the future. It is a dynamic process, both on a personal and collective level: a sort of 'in-themaking' idea, which is never complete, constantly in process and always in context. Regarding this, Zygmunt Bauman observed that, in our contemporary, liquid times, cultural identity is more of a 'target of effort', it is an objective, 'something one still need to build from scratch or to choose from alternative offers and then to struggle for and then to protect through yet more struggle' $(2004,16)$.

Refugees, more than any other displaced persons, experience both the struggle for cultural identity as a re-iterative process and the need to protect it. They are forced to become migrants, to assume the transient identities of the 'people in need', of the politically-displaced people with the wrong passport or of the superfluous people, who put strain on local communities. Refugees have to redefine themselves, sometimes often and in multiple contexts: from the moment they embark in an often dangerous journey towards their resettlement, 
they try keep together the known references of their cultural identities, while attempting to match the references, values and labels imposed by the new context.

Refugees do not belong, officially, to the hosting country and they cannot go back to their homes. Hence, they often struggle with the notions of 'there' and 'here', happiness and loss, being welcome and rooted and being outcast and displaced. They are what Bauman (2004) calls an 'underclass': a group excluded from a social and cultural system in a given time and space. They are subjected to forced cultural and social classifications and denied the privilege to claim their own cultural identity while experiencing a crisis of belonging. However, it is exactly through this crisis of belonging that the process for cultural identity redefinition and recognition, both on a personal and collective level, can happen.

The ambition to belong (to a group, to a context, or to a narrative) prompts a recollection of memories and stories about experiences, cultural practices and values. These memories and stories can then support the renegotiation and reassertion of the self, even in the context of displacement. Within this paper, this is particularly useful because it allows to recognise the tensions that refugees experience with regards to their personal reflections and the social classifications imposed on them. At the same time, the understanding of cultural identity in relation to refugees offers a purposeful framework to identify the visual discourses and multiple systems of references through which displaced people assert and express their agency, during coerced movements.

\section{The Methodological Approach}

This research methodological approach has been qualitative. It included both visual semiotics analysis and semi-structured interviews. This section will introduce the online repository, the Facebook page Syria.Art, where the visual data have been harvested and it will discuss the methods themselves.

The Syria.Art Facebook page as a visual repository of refugee memories Since the advent of Web 2.0 at the turn of the millennium, social media have fostered and allowed interactions between online users, often scattered around the world. This has facilitated connections, the possibility to interact with other group members (e.g. cultural, social, ethnic) anywhere and anytime and by the end of the first decade in the 2000s, social media had become an integral part of social life (van Dijck, 2013; Sergeant and Tagg, 2014). With regards to refugees, that social media are key for receiving and exchanging practical information about the journey, the places they are trying to reach, the rights they may have and the support services. In addition, social media can also serve the purpose of open repositories, easy to access and to connect with.

Between March 2016 and July 2016, several social media sites that host refugees' artworks were considered for the research. These included: 'Refugee Art'; 'Memory, place, heritage, displacement'; 'Athens Refugees Art'; 'Healing 
Refugees through Art'. They were all Facebook pages run by refugees and concerned with refugee art. The Facebook page 'Syria.Art', however, was the site which presented the most regular and updated information about the artistic heritage of refugees, primarily from Syria. Therefore, it was deemed appropriate for this study.

Syria.Art is an online repository of images of artworks produced by refugee artists, mainly Syrian, and displaced primarily in Europe since the 2015 refugee crisis. Although there are other Facebook pages (e.g. 'UK Refugee Welcome'; 'Refugee Research Network'; 'Refugee Aid') and social media (e.g. Instagram; themed blogs) narrating, almost in a journalistic way, the experiences of the journey of refugees, there are not many online platforms dedicated to the artistic heritage of refugee artists, created by refugee artists. The page has been set by a non-profit, non-religious and apolitical organisation, Syria.Art, led by refugee artists based in Nice, France. Its purpose is to be an online directory and gallery, promoting 'the work of distinguished and emerging Syrian artists' to the widest public (accessed November 302017.

https://www.facebook.com/pg/thesyrianart/about/?ref=page internal). ${ }^{i}$ The Facebook page posts more than once a day the images of different artworks, ranging from paintings to photographs, sculptures and videos, organised according to the featured artists. Most artworks are about Syria, before and after the war, and about Syrian people. The artists presented are identified by the page administrator who introduces the artists (their birthplace, education, current location and, when available, a link to the personal Facebook page); their artworks and the techniques in which they specialise. As an online repository of artworks produced by displaced artists, the page amplifies the possibilities for exchange and display of images as cultural products amongst Facebook's online communities. The meanings and stories generated by the images of these cultural products can offer us an insight into the memories of displacement and dispossession.

\section{Visual social semiotics}

The first step for the research involved the selection of the images of the artworks. This took place between September 2016 and January 2017. January 2017 was set as the cut-off date for the selection because the Syria.Art Facebook page re-presents, on a regular basis, the same images of the same artworks. Hence it was important to capture a distinctive spread of the artists and their works by delimiting the time for selection. ${ }^{\text {ii }}$ Overall the images of the paintings of fifty different artists were selected. The sampling procedure consisted of a random selection of the artists and associated artworks featured. Only every third image from the same artist was chosen, for a total of 150 artworks. The images were then numbered from 1 to 3 per artist, next to their surname (e.g. Tarabichi 1, Tarabichi 2 etc.).

Visual social semiotics was considered the most appropriate methodological approach for this study. Although rooted in the work of Ferdinand De Saussure (1958) and Roland Barthes (1972), visual social semiotics moves beyond the traditional semiotics' interest in structure and system and, as demonstrated by 
van Leeuwen (2000) consents a dynamic study of images as manifestations of social and cultural practices in-the-making. Within visual social semiotics, images are still considered as signs, made by a picture (the signifier) and a concept (the signified, to which the signifier refers to). This relation is arbitrary and it is meaningful only in a specific cultural context where people can access a variety of resources, through which social relations and interactions are performed and in this paper, between the creators of the images and the viewers/users (Lister and Wells, 2000).iii Hence, the interpretation of the images aims to unpack the layers of meanings associated, which may then be shared within a community. ${ }^{\text {iv }}$

In terms of the visual analysis, the notion of layered meanings was followed according to the work of van Leuween and Jewitt (2000). For each image, this study considered: 1) Denotation, which considers who or what is being depicted in the images of the artworks on the Syria.Art Facebook page. To address this point, the main features of the images were analysed and interpreted as expressed in the paintings; and 2) Connotation, which focuses on the types of ideas are conveyed through what is represented and how is this represented. This point was addressed by trying to decode some of the symbols emerged from the images. The pictures' layers of denotation and connotation were arranged according to a table. The table detailed each image according to the name of the artist, the title and description of the painting when provided by the artists themselves, the 'Denotative Signifier'/'Denotative Signified' and the 'Connotator'/'Connotation' (van Leuween, 2000). This allowed for an identification of the recurring topics as the prominent visual stories, as being deployed on the online repository. Additionally, such organisation of the data consented to identify and interpret the visual narratives developed.

It is important to specify that in the context of this article, visual social semiotics is primarily used as a micro-analytical tool applied to an online repository (the Facebook page). As such, visual social semiotics can help in bringing out the visual narratives about the individual and collective memories emerging through the paintings displayed online: however, it is not used to examine how the online medium (in this case Facebook) has affected the online circulation and reception of the artworks, or how the users of Facebook page have been interacting with the content displayed online. A more in-depth, subsequent study about different types of artworks and other online platforms would need to be grounded on the analysis of data generated in conjunction with other methods (e.g. content analysis, focus groups, etc) and over a longer project and time span.

\section{Semi-structured interviews}

The second step of the study aimed to capture a deeper understanding of the visual discourses emerging through the images. Therefore, a set of semistructured interviews were conducted between August 2017 and December 2017. Unfortunately the author could interview only ten of the fifty artists identified:v indeed, not all the contacted artists agreed to take part in the research, due to personal circumstances. Participants shared two main 
elements: 1) they specialised in the same mode of creative expression and 2) they were all displaced artists, with the same geographical background.

The interviews focused on three main areas: their personal story/identity before the forced migration; the inspiration and motivations for their works and the denotation/connotation of the images considered in this study. However, the interviewees were encouraged, if they wished, to discuss other works of their art displayed on Syria.Art. Given the different geographical locations of the artists (France, Belgium and South England), the interviews were all conducted as skype video calls: the artists received the list of questions two weeks ahead of the interview so that they could think through their answers before the call. As requested by most of the interviewees, their anonymity was maintained and in the data analysis and discussion, participants were coded as A, for 'Artist', plus a number in progression from 1 to 10 . The data collected from the artists' interviews were then used to inform and complement the analysis of the images. This was done to understand whether artists' intentions supported the visual narratives identified.

\section{Interpreting the data: visual narratives about the universal migrant experience}

Through the denotation/connotation analysis and the individual interviews three shared themes, as visual narratives, were identified: The Necessity of the Journey; Living cultures in everyday practices and The Keepers of Cultural Heritage and Identity. vi

\section{The necessity of the journey}

Leaving one's home and loved people behind is probably one of the most difficult choices that people have to make, even when their own lives and safety are at stake. It means to leave behind not only tangible things, but also part of their identity, stories, traditions, dreams and plans: it means to be reduced to the status of 'bare life', 'that is, life stripped of political identity and exposed to the state's unmediated application of power' (Demos 2013, xiv). What is more, embarking in a risky journey, towards an unknown and yet, perceived and hoped 'safe' place is very much an unsettling feeling. And yet the journey, or moving out from their own country, for refugees and forced migrants is imperative: they must attempt to reach a land which they may call home, even if for a little while (Fig.1, Al Omari1).

The images of the paintings analysed show that the theme of forced mobility as a necessary journey is a recurring one: although the representations relating to it vary according to the personal stories the artists want to narrate, those paintings that deal with the idea of the movement (individual or collective) and its necessity are all also concerned with the notions of place and belonging (Fig. 2, Al Jazairi1; Fig.3, Fahad2). The most common denotative signifiers within this theme are boats, sometimes with refugees, sometimes with one person only, and people on the move, either on foot or on a horse. Their denotative signified, thus, is clearly relating to the idea of a journey, personal or collective, and yet both metaphorical and real: it is a journey through the human condition. This is 
very much in line with Agier's observation $(2008,28)$ : each displaced person, each refugee 'carries with them the experience of being undesirable and placeless' but at the same time, each refugee carries the will to survive and determine their own fate.

The untitled painting (Fig.4, Ali2) by Amer Dhahi Ali for examplevii represents a woman who is travelling, seemingly on her own. She carries with her several bags and she is the central subject (e.g. the denotative signifier) of the artwork. The woman has her head reclined towards the left of the painting, in a pensive and poignant way: it is possible to assume that she is a forced migrant (e.g. denotative signified), who has to leave her home and her loved ones behind as the high number of luggage and of the sad expression on her face indicate. However, it is worth pointing out that the depicted scene goes beyond the mere idea of the forced move: indeed, special importance in the reading of the image must be given to the posing of the other objects and elements, such as the pile of bags, the clear blue sky, where the meaning comes from the way they have been represented in relation to the main subject. Through their skilled positioning, the surrounding objects not only 'suggest' a specific idea (a long, lonely journey where all the most important and valuable items must be carried along) but they also symbolise the ordeal of a necessary, painful and upsetting change of status in somebody's life: from a citizen to the person in need. This is stark contrast with the beautiful day represented in the painting. The surrounding objects amplify the individual awareness of a loss (e.g. loss of a place, loss of the sense place and belonging) and therefore 'the transformative potential of dislocation that decentres the very basis of national identity' (Demos 2013, xix).

In a way, this visual relation and correlation between the different visual elements of the image consent a more immediate conceptual connection between the micro individual experience of the forced migrants and the macro socio-political context of the migrants and refugees' crisis. Both in the individual interviews and the analysis of the images, it emerged that the act of travelling, represented in all the images belonging to this theme and exemplified by the discussed painting, indicates the visual story of a necessary, intimate and yet public journey: it is not only a forced journey towards a new, perhaps safe place, but it is also and foremost a personal journey of transformation. This confirms the explanation that Rosinska (2011) gives with regards to the 'emigratory experience': a challenging process, shaped by a sense of estrangement, sadness, a sense of loss, the wanting of a meaning in life and a loss of identity. It is a journey which will bring the traveller/forced migrant/refugee to assume new, unexpected and most certainly unwanted, identities: it is a transformative experience, towards which anyone, going through major personal changes, can identify with. For instance, as A3 observed: 'refugee or migrant, it does not matter to me. We become people without a land, we become refugees because we are forced out of our places and to flee death and war, it is not optional, it is what we become'. 
The artworks belonging to this theme share the idea of a metaphorical and nonmetaphorical journey of transformation and difference: the represented narrative becomes a account of the route that refugees and any displaced peoples have to go through to 'constantly produce and reproduce themselves anew' before reaching the intended destination (Hall 2000, 23).

\section{Living cultures in everyday practices}

The theme Living cultures in everyday practices is concerned primarily with the emotions and reflections generated during the forced movement. Maruska Svasek (2012) has observed that while such emotions are intrinsic to human life and relatively straightforward to elaborate and define, the subsequent processes can be complex. The idea or the memory of a forced journey, and hence the idea of the physical and emotional changes that go with it, is a trigger for a wide array of responses. These responses can contribute to the formation of reflective discourses, restorative practices or even embodied memory experiences but they are also concerned with anger for the war, grief for the lives lost, nostalgic celebrations of a glorious past and legends about local culture and its traditions. Through this theme, the engagement with past, present and future situations becomes a way to remove displaced individuals from 'a vacuum form of experience with no references, no criteria of definition, nor modes of identification' (Makaremi, 2011, 75) and recontextualise them into a system of living, cultural values and practices.

The symbols associated with this theme, indeed, reflected a cultural system of reference, which included a variety of emotions, memories of everyday life and past stories: it is through this cultural system that refugee groups can become again visible to themselves and to others (Assmann, 1995) (Fig.5, Ballan3). Within the Living cultures in everyday practices theme, recurring denotative signifiers/denotative signified included: the house as the representation per excellence of the inner self; different masks as the symbols of the multiple identities, which human beings assume throughout their lives; but also, music and dance as happier expressions of human creativity, even in troubled and difficult times. The symbol of home as the alcove of people's identity, as the locus where the humanity of the refugees is still intact, has been depicted widely across the paintings examined: for example, the untitled artwork (Fig.6, Hussein1) by Ali Hussein represents a woman, visibly scared, standing next to a table in her kitchen. The wall, as explained by the artist himself, is covered with photographs and postcards of bygone people and places. The woman looks directly and intensively at the viewers and by doing so, she establishes a degree of intimacy with them: we, the viewers, are not looking at her in her kitchen but it is like if we are there with her ready to listen to find out more about her life, her story and her emotions. Although the objects around suggest additional meanings surrounding the theme of the painting, it is the power of the represented human figure that can express and narrate, through the intensity of her eyes, a story about a once-happy family home, which is now bearing the loneliness of the war through the eyes of those who have been left behind. 
All these narratives, practices and discourses about home, emotions and identities gravitate, as all the interviewees have pointed out, around the need to preserve a collective memory or set of collective memories of the human experience affected by the war and displacement, like also in the work by Rasha Adnan (Fig.7, Adnan1) and Boutros Al-Maari (Fig.8, Al-Maari3). These memories can be associated with objects, people and events as A8 explains:

I have a lot of people with make-up [in my paintings] this is because when I was a child, in Syria they were putting a show with puppets from Ottoman times called Karagöz; these puppets have a lot of makeup, and when I was a child, I always watched Karagöz, every Sunday. These people exist in my paintings.

The images of this theme allow for a visual, shared version of a recent past, which, as Erll observes, is oriented towards the transmission of cultural knowledge and towards 'the needs and interests of [a] group in the present and thus proceeds in an extremely selective and reconstructive manner' $(2011,17$; see also Assmann, 1995). Therefore, the visual narratives are a type of performative, collective consciousness, which links past and present in places where the distance with home is great. As pointed out by the interviewees, the domestic sphere and the family are recognised as important sites for the transmission of group identities through food, dress language oral narratives, and modes of socialisation. Expressions of their distant but living culture are hence embodied into the everyday practices of individuals engaged in ordinary jobs, in the nurturing the youngsters, or in the enjoyment of familiar leisure activities.

The keepers of cultural heritage and identity Many of the paintings considered in this paper are a testament to the resilient nature of humanity, where resilience is understood not only as the ability to cope with a terrible, life changing situation (e.g. the forced journey; the horrors of the war; the resettling in a new country) but also as the creative skill to remember, celebrate and transmit individual strands of collective identities and memories. As pointed out by Halbwachs (1992), collective memories, in fact, are the sums of the memories of an individual and operate within specific sociocultural contexts and allegiances. Above all, the artworks relating to this theme are nostalgic representations of the childhood lost through the war in Syria and the shattered lives of the people who have been affected by the war (Fig.9, Zantha1). However, such artworks are not concerned with pity or commiseration for the subjects represented. On the contrary, they foster understanding and empathy for the human condition and resilience of displaced individuals.

When asked about their artworks, all the interviewees shared the feeling and need to represent the people they knew and the impact of the war on them, mainly in terms of change: from normal people, with normal jobs, hopes, fears and problems to the victims of the war: 
It is like if there are two persons in my paintings: before the war, I was inspired by things in my place, I was presenting Syria in modern way, but after the war, what inspires me is the war itself. The violence inspires me. I know I am now outside the country, but I faced violence there I saw violence, and this violence is that makes me to want to transmit what I saw: the victims of violence and tell about them in my pictures. (A6)

The paintings falling under this theme are perhaps the most poignant works amongst the ones examined and this perhaps is because of their intimate nature: they are primarily about the people, especially women and children, the artists used to know back in Syria, the daily rituals, the games played by children in the streets, the stories heard in the neighbourhoods. They represent individuals, objects and places that are resisting, at least in the artists' memories, to the war and its destruction. Their crisis of belonging and of the absence of the self is the trigger for the reiterative process of identity formation: the identity struggle of the Baumanian underclass is fully exemplified through this theme and through the faces of the people portrayed in the various paintings, like in the ones of $\mathrm{A} 10$.

Similarly, a range of themes, profoundly ingrained in his cultural and historical Syrian heritage, provide the source of inspiration for Khaled Takreti's works. As he explains in a short introduction on his Facebook page, through his paintings he wants to represent both the recent conflicts in Syria and the consequences and effects that they have had on the population. Takreti wants to narrate the stories of the men and women in Syria, evoke memories of displacement, and memories from his own childhood days in Damascus. Like the other artists, Takreti (Fig.10, Takreti2) attempts to create a corpus of stories which can preserve and visually transmit Syrian culture and traditions. This seems to be happening particularly through the representations of women and children who, as the subjects of the artworks, acquire new meanings that go beyond the ones of the victims of the wars and of the humanitarian crisis: these new meanings are very much concerned with the idea of women and children as the key keepers of cultural traditions and (re)producers of cultural identities. For example, two artists (A2 and A7) have embedded their childhood memories in their paintings and through them they elicit personal stories about their mothers, grandmothers and old female friends (Fig.11, Mohammed2): A7 remembers that when he was living in his grandparents' house, many of the neighbours 'were consulting my grandmother and offering her coffee, as it is tradition in Syria. I could not drink coffee so she was putting the bread in the coffee so I remember the taste of the coffee very well'.

The painting (Tarabichi3, Fig.12) titled 'Nocturne' represents a woman peacefully sleeping, while covered by a printed blanket. On the blanket, there are the images of a historic urban landscape (which, as the artist explained, represents the city of Aleppo) and the woman with her arm posed on the it, gives the impression that she is protecting the blanket/town and cherishing it: 
she may be dreaming about it or she may just feel close to the place represented by touching the blanket. The visual story narrated through the painting is, indeed, about a protective and tender gesture towards a beloved object, the blanket, and towards the memory of Aleppo, which she embraces and holds to, notwithstanding a physical distance.

\section{Concluding observations}

As Gillian Rose $(2012,2)$ explains in her analysis of visual methods, 'images are never transparent windows onto the world: they interpret the world; they display it in a very particular way, they represent it'. The images of the artworks on the 'Syria.Art' Facebook page display the ways in which Syrian artists interpret their (past) world now: a world tainted by war and loss, and yet populated by memories of dear ones, nostalgic reminiscences of everyday life and rituals in their homes. It is the interpretation of this world that Syrian artists, as the custodians of bygone times and never-forgotten stories, want to share with others forced migrants, refugees, art lovers or just other Facebook users. Through the membership to a social group, being this either the one of 'Refugee and forced migrants' or the one of the 'Syria.Art' Facebook page, refugee artists not only are able to acquire, localise and recall their memories through visual records, but they also able to set the basis for a wider communication of their cultural traditions and identity (Halbwachs, 1992).

The three themes identified, both through the visual analysis and the interviews, represent visual narratives that tell us about the paused, almost timeless stories of a universal, human journey, which is, primarily, about transformation and resilience. The themes illustrate a range of creative, human activities and certainly allow a deeper reflection on the relationship between different elements of the lives of the people they represent. The overlapping and inextricable connection between individual memory (the one of the refugee, the one of the displaced artist) and collective memory (the one of a global society which is witnessing the refugee crisis) becomes evident. Their bond sheds a light, primarily on a visual level, on the current changing and boundary-less notions of cultural identity and traditions, which in this case are not dominated by the media-led 'humanitarianism'. Especially in an online, non-physical context, collective and personal memories become strongly connected to the idea of and longing for 'home', which however, within the context of displacement, cannot be located anymore in tangible, material spaces but only in bygone times and memories which are redefined and re-created almost daily, almost as a form of resistance and resilience (Halilovich, 2013). At the same time, this corpus of images assumes a cathartic function: on the one hand, it offers a platform to refugee artists to tell their stories and to express all their feelings through a chosen form of art. On the other hand, though, it is a visual and cultural trigger that allows refugees (through their meaningful visual narrative sequences about the reinterpretation of the past based on memories of displacement), to recognise themselves as active, and lawful contributors to the global cultural and visual discourse about cultural identity, cultural traditions and forced migration. In this endeavour, online platforms like the Syria.Art Facebook page are purposeful and key fora, which help to raise awareness 
about cultural traditions lost to wars, offer a space to discuss and possibly overcome social misunderstandings, to acknowledge and share different understanding about the trauma of displacement and dispossession. This body of images and memories, generated and displayed online, hence, is situated in the routine and everyday experienced realities of the refugees as newcomers, which are gradually, not without tensions, becoming part of the histories and cultural fabric of the hosting society. These shared histories in the making have the potential to shape our own memories and stories as Europeans and may become, eventually, part of the visual resources about cultural practices and

forced migration in the twenty first century.

\section{Acknowledgments}

I would like to thank all the participants of this research, who generously shared their time, experience, and personal memories with me. I am also grateful to Dr Kostas Arvanitis for his constructive comments.

\section{References}

Agier, M. (2002) On the Margins of the World: The Refugee Experience today. Cambridge: Polity Press.

Arcimaviciene, L. and Baglama, S. H. (2018) Migration, metaphor and myth in media representations: the ideological dichotomy of 'them' and 'us', Sage Open: 1-13.

Assman, J. (1995) Collective memory and cultural identity, New German Critique, 65: 125-133.

Baider, F. and Kopytowska, M. (2017) Conceptualising the Other: Online discourses on the current refugee crisis in Cyprus and in Poland. Lodz Papers in Pragmatics, 13, 2: 133-152.

Barthes, R. (1972) Mythologies, London: Vintage Books.

Bauder, H. (2009) Humanitarian Immigration and German National Identity in the Media, National Identities, 11: 3, 263-280.

Bauman, Z. (2004) Identity: Conversations with Benedetto Vecchi, Cambridge: Polity Press.

Boyle, P., Halfacree, K. H., and Vaughan R. (eds). (2013) Exploring Contemporary Migration. Oxon, New York: Routledge.

Castles, S., de Hein H., and Miller, M. (2014) The Age of Migration: International Population Movements in the Modern World. New York: Palgrave MacMillan.

Chatty, D. (2014) Anthropology and forced migration. In: E. Fiddian-Qasmiyeh, G. Loescher, K. Long, and N. Sigona (eds) The Oxford Handbook of refugee and forced migration studies, Oxford: Oxford University Press, 74-85.

Chouliaraki, L. (2012) Between Pity and Irony - Paradigms of Refugee Representation in Humanitarian Discourse'. In K. Moore, B. Gross and T. Threadgold (eds) Migration and the Media, New York: Peter Lang, 13-31.

Chouliaraki, L. (2013) The Ironic Spectator: Solidarity in the Age of PostHumanitarianism. Malden: Polity Press. 
Demos, T. J. (2013) The Migrant Image: The Art and Politics of Documentary During Global Crisis. Durham and London Duke University Press.

van Dijck, J. (2013). The Culture of Connectivity: A Critical History of Social Media, Oxford: Oxford University Press.

Elie, J. (2014) Histories of refugees and forced migration studies. In: E. FiddianQasmiyeh, G. Loescher, K. Long, and N. Sigona (eds.) The Oxford Handbook of refugee and forced migration studies. Oxford: Oxford University Press, 23-35.

Erll, A. (2011) Memory in culture. New York: Palgrave Macmillan.

Esses, V., Hamilton, L. and Gaucher, D. (2017) The Global Refugee Crisis: Empirical Evidence and Policy Implications for Improving Public Attitudes and Facilitating Refugee Resettlement, Social Issues and Policy Review, 11, 1:78-123.

Esses, V., Medianu, S. \& Lawson, A. (2013) Uncertainty, threat, and the role of the media in promoting the dehumanization of immigrants and refugees, Journal of Social Issues, 69, 3:518-536.

Gatrell, P. (2015) The making of the modern refugee. Oxford: Oxford University Press;

Gouriévidis, L. (2014) Museums and Migration. History, memory and politics. London and New York.

Goodnow, K., Lohman, J., and Marfleet, P. (eds). (2008) Museums, the media and refugees: stories of crisis, control and compassion. New York, Oxford: Berghahn Books.

Halilovich, H. (2013) Places of pain, forced displacement, popular memory and translocal identities in Bosnian war-torn communities. New York, Oxford: Berghann.

Halbwachs, M. (1992) On Collective Memory. Chicago, University of Chicago Press.

Hall, S. (2000) Cultural Identity and Diaspora. In: N. Mirzoeff (ed) Diaspora and Visual Culture. Representing Africans and Jews, London and New York: Routledge, 21-33.

Hathaway, J. C. (2007) Forced Migration Studies: Could We Agree Just to 'Date'? Journal of Refugee Studies, 20, 3: 349-369.

van Leeuwen, T. (2000) Semiotics and iconography. In: T. van Leeuwen, and C. Jewitt (eds) The Handbook of Visual Analysis, London: SAGE Publications, 92-118.

Lawler, S. (2008) Identity. Sociological perspectives. Cambridge: Polity Press.

Lister, M. and Wells, L. (2000) Seeing beyond belief: cultural studies as an approach to study the visual. In: T. van Leeuwen, and C. Jewitt (eds) The Handbook of Visual Analysis, London: SAGE Publications, 61-91.

Jewitt, C. and Henriksen, B. (2016) Social Semiotics Multimodality. In: N.-M. Klug and H. Stöckl (eds) Handbuch Sprache im multimodalen Kontext, Berlin/Boston: Walter de Gruyter GmbH, 145-164.

Makaremi, C. (2011) The waiting zone, In: J. Creet and A. Kitzmann (eds) Memory and Migration: Multidisciplinary Approaches to Memory Studies, Toronto: University of Toronto Press, 68-92.

Malkki, L. (1996) Speechless Emissaries: Refugees, Humanitarianism and Dehistoricization, Cultural Anthropology, 11, 3: 377-404. 
Moores, S. (2012) Media, Place and Mobility. Houndmills: Palgrave Macmillan.

Pamment, J., Dolea, A. and Ingenhoff, D. (2017) The European refugee crisis: organisational responses and communication strategies, Journal of Communication Management, 2, 4:322-325.

Rose, G. (2012) Visual Methodologies. London: SAGE.

Rosinska, Z. (2011) Emigratory experience: the melancholy of no return. In: J. Creet and A. Kitzmann (eds), Memory and Migration: Multidisciplinary Approaches to Memory Studies, Toronto: University of Toronto Press, 2942.

Rotas, A. (2004) Is 'Refugee Art' Possible?, Third Text, 18, 1: 51-60.

de Saussure, F. (1958) Course in General Linguistics. New York: Colombia University Press.

Scholten, P., Collett, E. and Petrovic M. (2016) Mainstreaming migrant immigration? A critical analysis of a new trend in integration governance, International Review of Administrative Sciences, 83, 2: 283-302.

Sergeant and Tagg. (2014) Introduction: the language of social media. In P. Sergeant and C. Tagg (eds) The Language of Social Media. Identity and Community on the Internet, London: Palgrave MacMillan, 1-20.

Sigona, N. (2014) The politics of refugee voices: representations, narratives and memories, In: E. Fiddian-Qasmiyeh, G. Loescher, K. Long, and N. Sigona (eds) The Oxford Handbook of refugee and forced migration studies, Oxford: Oxford University Press, pp.369-382.

Skartveit, H.-L. and Goodnow, K. (eds). (2010) Changes in Museum Practice: New Media, Refugees and Participation, Berghahn Books.

Sontag, S. (2003) Regarding the pain of others. Penguin Books.

Svasek, M. (2012) Emotions and Human Mobility: Ethnographies of Movement. London and New York: Routledge.

Whitehead, C., Eckersley, S., Lloyd, Katherine and Mason, Rhiannon (eds). (2016) Museums, Migration and Identity in Europe: Peoples, Places and Identities. London and New York: Routledge.

Wright, T. (2002) Moving Images: the media representation of refugees, Visual Studies, 17,1, 2002: 53-66.

\section{Web resources}

"Syria.Art

Facebook

Page."

Available

at: https://www.facebook.com/pg/thesyrianart/about/?ref=page internal (accessed 30 November 2017)

"Global Migration Trends". Available at https://www.iom.int/global-migrationtrends (accessed December 5 2018) 


\section{Figures}

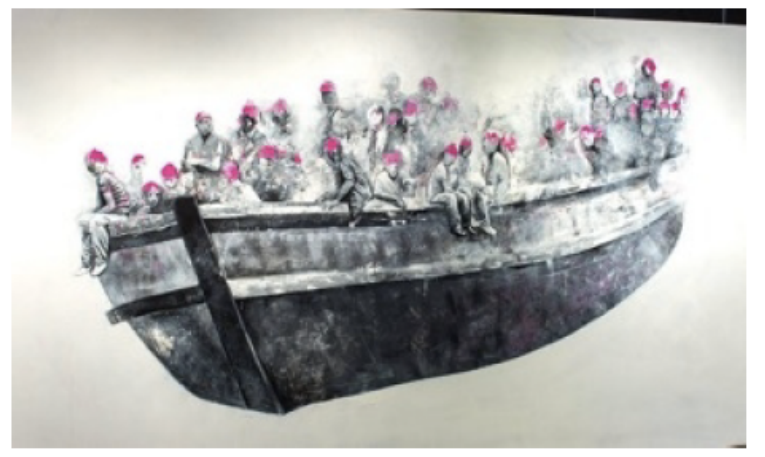

Figure 1. Painting titled: "The Boat" by Abdalla Al Omari @. Source: Syria.Art Facebook page. 


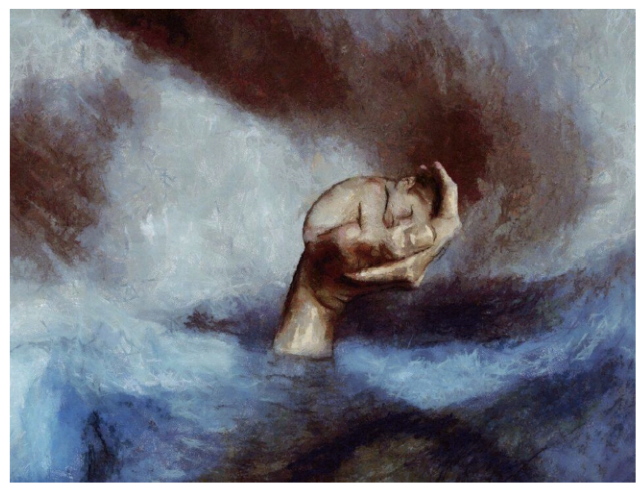

Figure 2. Painting titled: "Lampedusa and Refugees" by Wissam Al Jazairi $\odot$. Source: Syria.Art Facebook page.

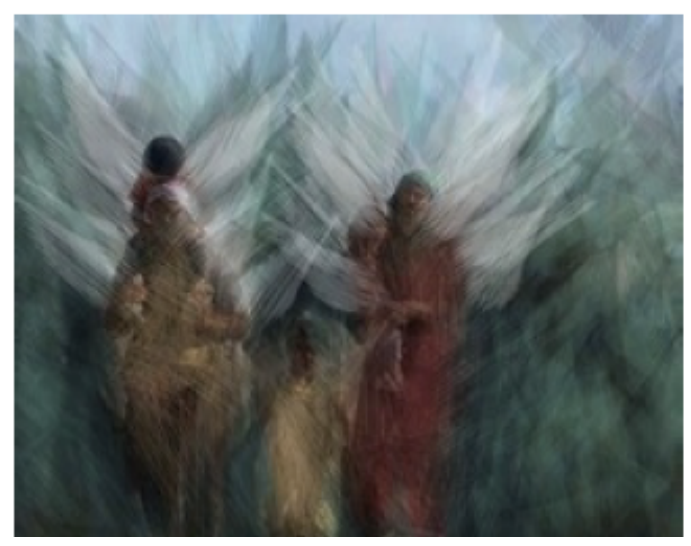

Figure 3. Untitled painting by Amrd Fahd $\odot$. Source: Syria.Art Facebook page. 


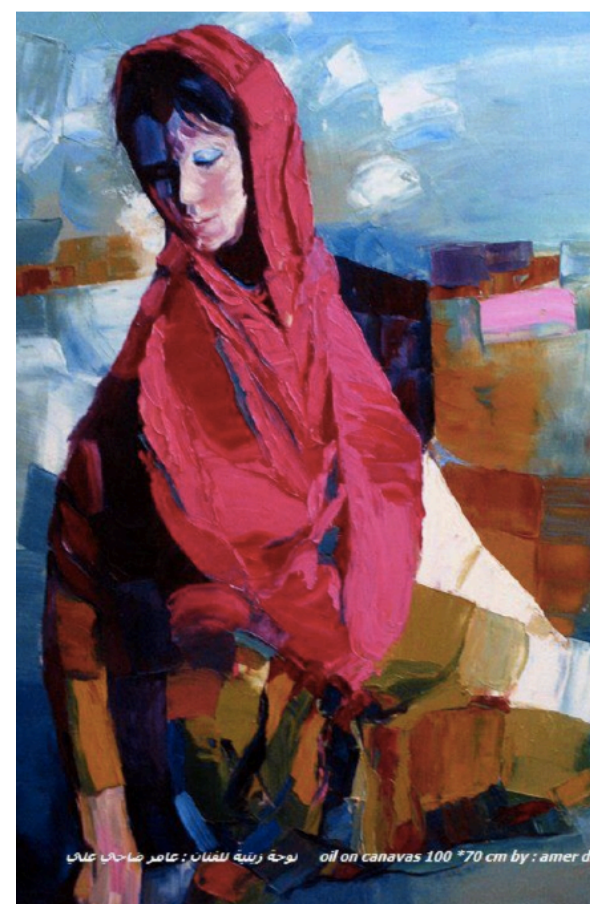

Figure 4. Untitled painting by Amer Dhahi Ali @. Source: Syria.Art Facebook page.

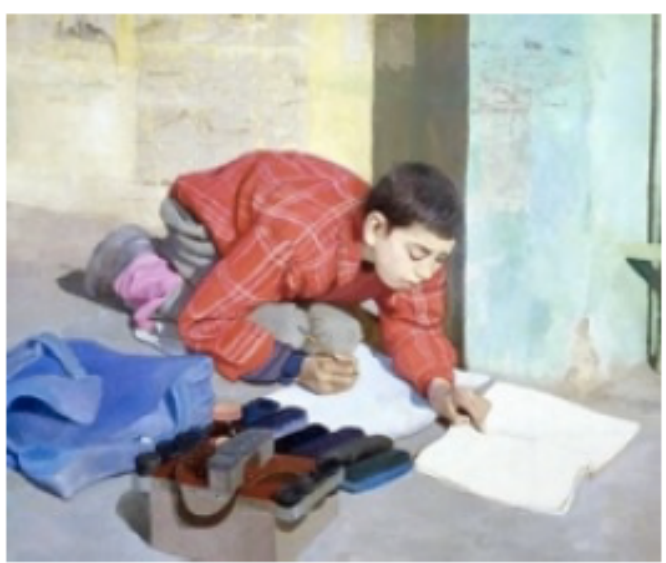

Figure 5. Untitled painting by Houssam Ballan @. Source: Syria.Art Facebook page. 


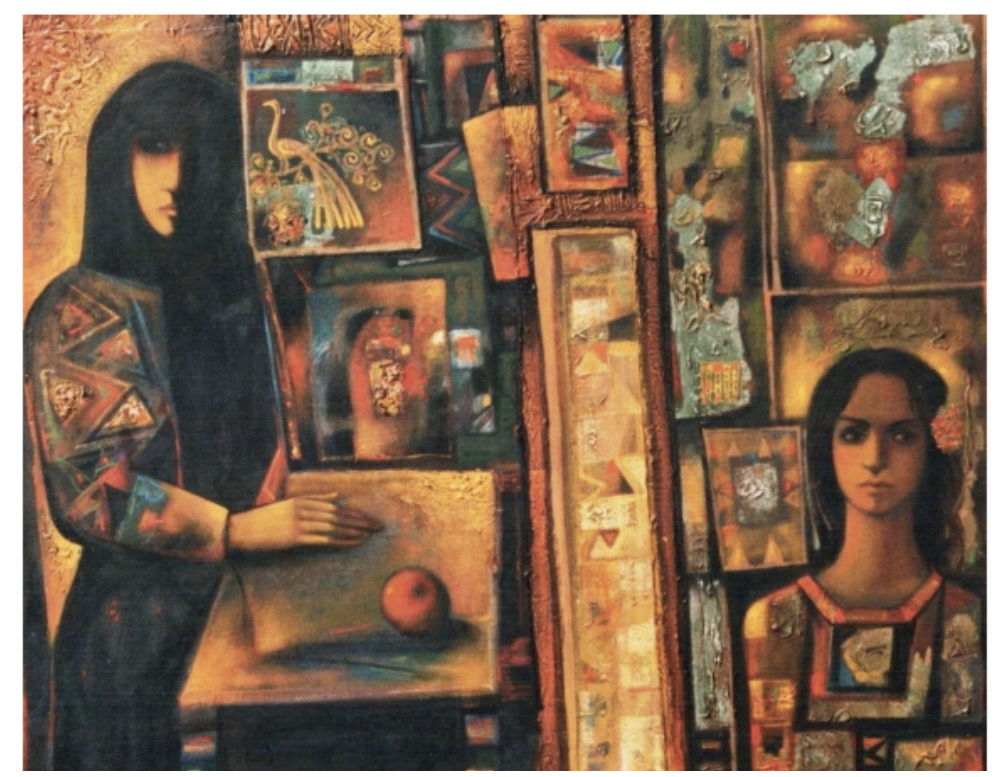

Figure 6. Untitled painting by Ali Hussein $\odot$. Source: Syria.Art Facebook page.

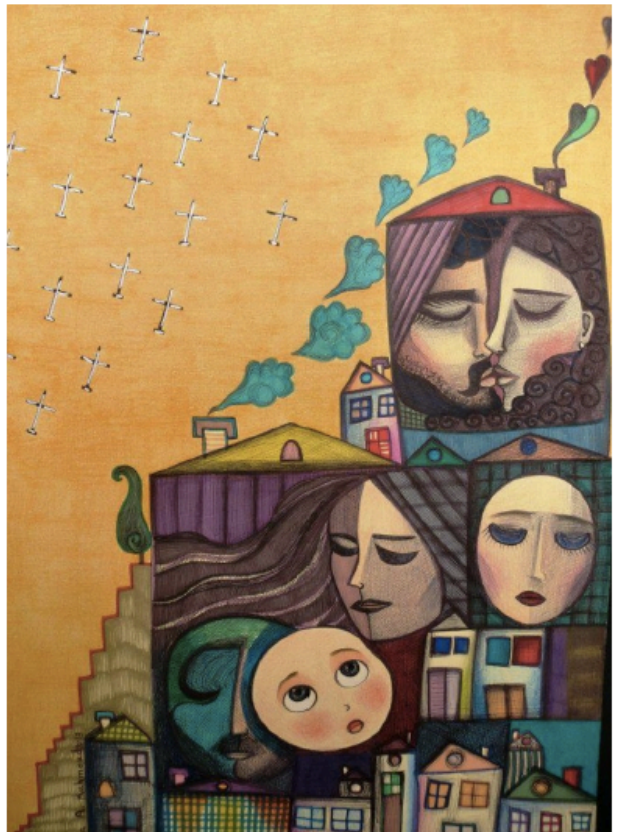


Figure 7. Untitled painting by Rasha Adnan $\odot$. Source: Syria.Art Facebook page.

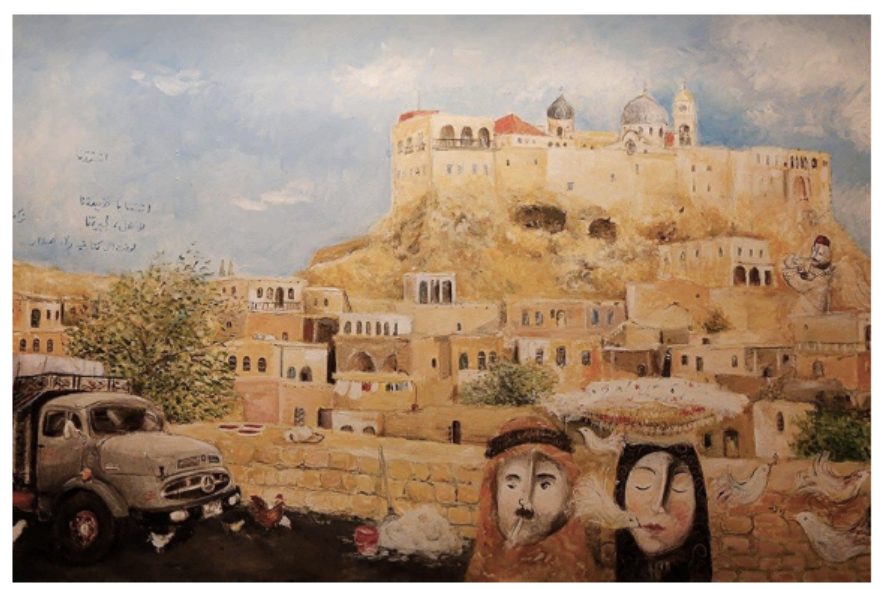

Figure 8. Painting titled: "Memories of the days" by Boutros Al-Maar @ $\odot$. Source: Syria.Art Facebook page.

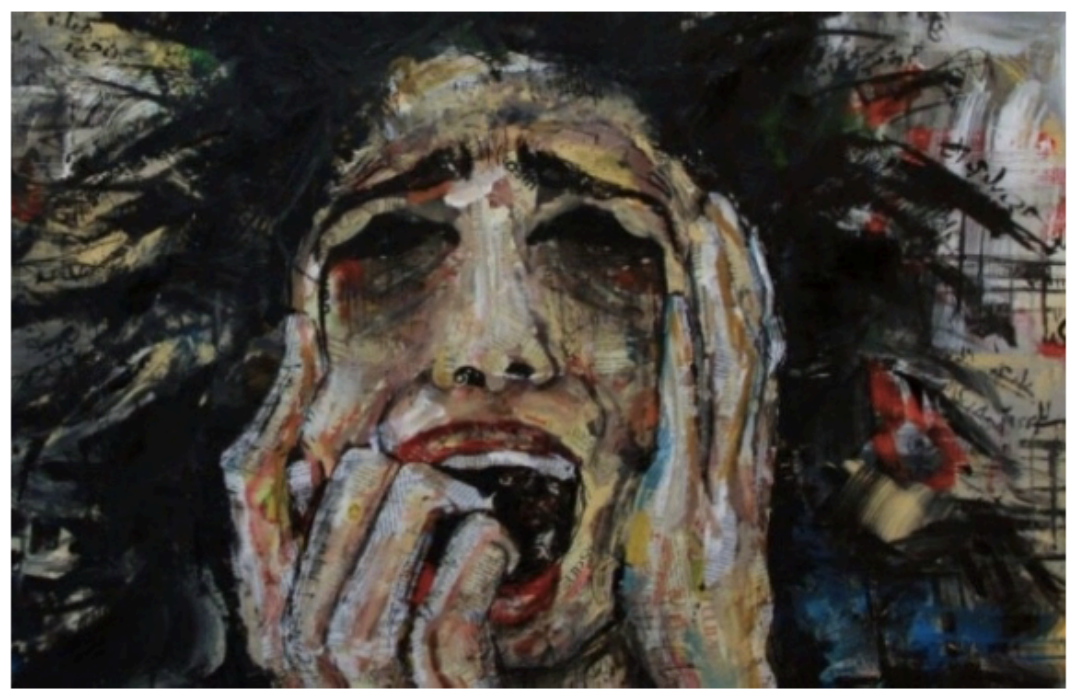

Figure 9. Self-portrait by Nour Zantha @ . Source: Syria.Art Facebook Page. 


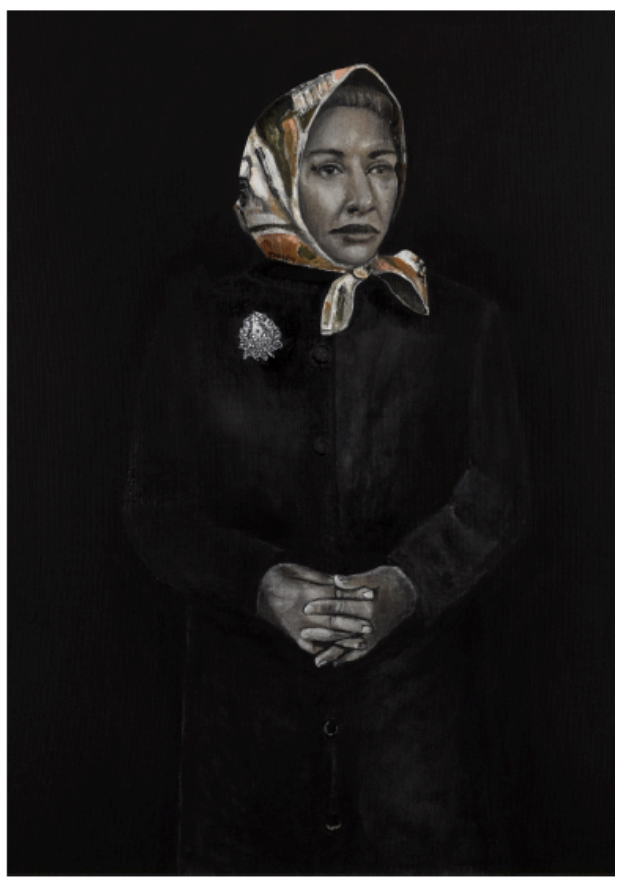

Figure 10. Painting titled: "Les femmes de la guerre", by Khaled Takredi @. Source: Syria.Art Facebook page.

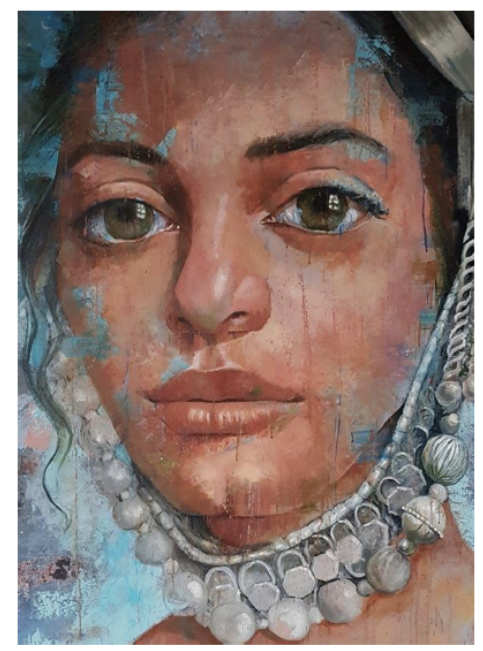

Figure 11. Untitled painting by Maysa Mohammed @. Source: Syria.Art Facebook Page 


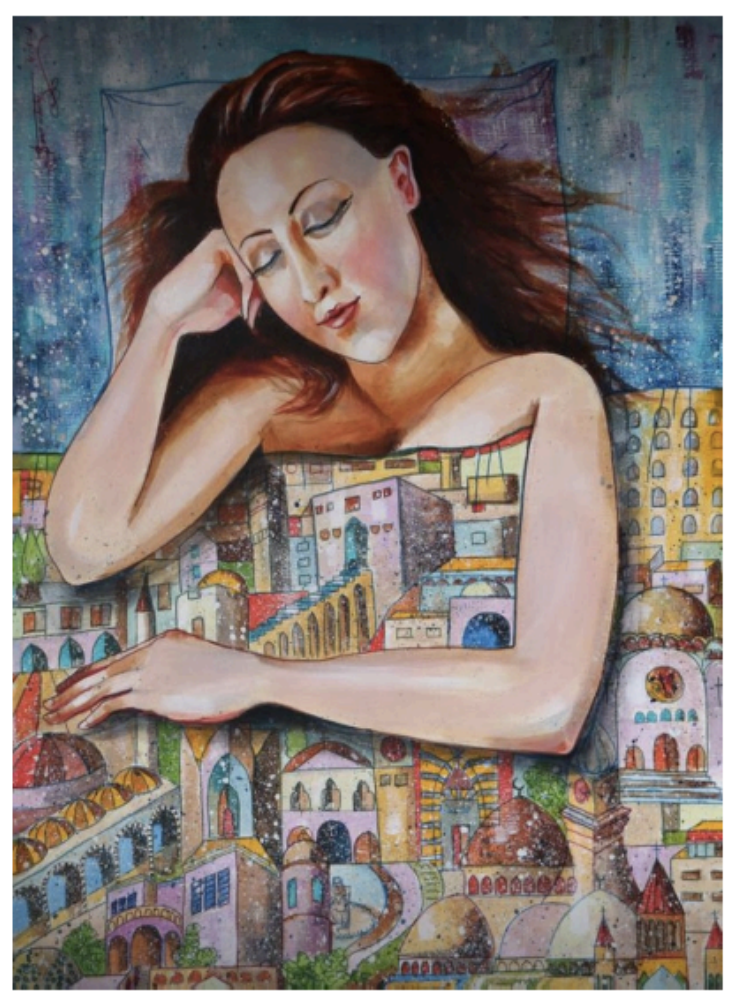

Figure12. Painting titled: "Nocturne" by Samer Tarabichi @. Source: Syria.Art Facebook Page.

\footnotetext{
i It is worth mentioning that when this research started the organisation Syria.Art was present only via Facebook (in English) and as a website (in French). Recently, Syria. Art has developed also a presence on Instagram: however, the display of the images on Instagram is much more chaotic because it does not follow an organised presentation of the artists and artworks. Therefore, Instagram was not considered suitable as a visual repository for this study.

ii This study is not definitive as a visual semiotic study: hence it is not yet completed.

iii The principles are: 1 ) people see the world through signs; 2 ) the meaning of the signs is created by people in a specific system and it does not exist outside; 3) every semiotics system has a variety of resources of making meaning.

ivlt should be pointed out though that like all research approaches, also visual social semiotics has its limitations (e.g. the analytical and personal gaze of the researcher on a limited number of images) and hence the mere analysis of the images might not be sufficient (Jewitt and Henriksen, 2016).

$\checkmark$ Of the ten interviewed artists eight were male and two were female. The interviewees were aged between twenty-four and fifty-four. They all had at least a BA and three of them had a PhD.

vi Of the 150 images analysed, 120 focus human subjects (women, men and children), while the remaining 30 were images representing urban landscapes. Of the 120 images, 70 images depicted women of different ages; 35 focused on children (either on their own or with an adult, usually female) and 15 depicted adult male subjects.
} 
viiAmer Dhahi Ali does not have an individual FB page and the Syria.Art FB gallery does not include any background information about him: he is just identified as 'Syrian Artist'. 
Visual Communication <onbehalfof@manuscriptcentral.com>

Wed, 3 Apr, 09:08

to me -

03-Apr-2019

Dear Dr. CATALANI,

It is a pleasure to accept your manuscript entitled "Refugee artists and memories of displacement: a visual semiotics analysis" in its current form for publication in Visual Communication.

As you can see from the comments of the reviewers who reviewed your manuscript, both suggested to accept your paper after a very good revision. The second reviewer in fact has some further suggestions, but I myself had a look at your manuscript as well and don't think they are necessary. I am thus very happy to accept your paper in its current form.

The manuscript version accepted is the one that will be used to produce your proofs (we will take care of de-anonymising it). You will have the chance to make changes in your proofs, but these will have to be limited enough to be incorporated in the proofs. In case you need to make more extensive updates, kindly let us know within 2 days from this email. Please note that the system of manuscript production will not allow us to consider a revised version afterwards.

Thank you for your fine contribution. On behalf of the Editors of Visual Communication, we look forward to your continued contributions to the Journal.

Sincerely,

Dr. Janina Wildfeuer

Editor, Visual Communication

wildfeuer@uni-bremen.de 